J. Lake Sci. (湖泊科学), 2013, 25(4):558-564

http: //www. jlakes.org. E-mail : jlakes@niglas.ac.cn

(c) 2013 by Journal of Lake Sciences

\title{
河西走廊花海古湖泊全新世白云石的发现及其环境意义”
}

\author{
李卓仑, 陈 晴, 王乃昂, 李 育, 吕行行 \\ (兰州大学资源环境学院,兰州大学干旱区水循环与气候变化研究中心,兰州 730000)
}

\begin{abstract}
摘 要: 通过对河西走廊花海古湖泊沉积物的 X 衍射分析发现, 全新世期间有明显的白云石沉积. 岩性、沉积过程、石膏 以及 $\mathrm{Fe}^{3+}$ 含量的变化表明, 花海湖全新世白云石沉积环境以还原环境为主, 即还原环境利于白云石的形成, 为白云石的 成因研究提供了新的证据. 白云石作为碳酸盐矿物, 可以反映湖水盐度, 但并非直接指示了湖水的咸化. 随着湖水盐度的 进一步增加, 在硫酸盐型湖泊中, 白云石含量随盐度的增加而相应减少, 表明利用白云石分析湖水盐度时需要结合其他 矿物进行分析. 结合石膏含量的变化, 花海湖全新世时期白云石含量的变化可以揭示该区域湖水盐度的变化. 在 10.47一

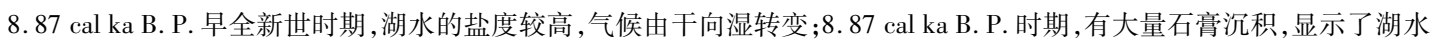

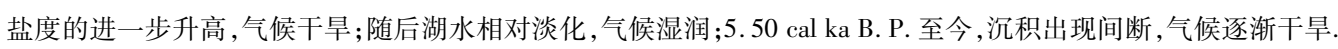

关键词: 全新世; 白云石;石亳; 花海湖;河西走廊;湖泊演化

\section{Discovery of dolomite deposition during the Holocene and its environmental significance in Lake Huahai, Hexi Corridor}

LI Zhuolun, CHEN Qing, WANG Nai'ang, LI Yu \& LÜ Hanghang

(College of Earth and Environmental Sciences, Center for Hydrologic Cycle and Climatic Change in Arid Region, Lanzhou University, Lanzhou 730000 , P. R. China)

\begin{abstract}
Obvious dolomite deposition during the Holocene was found by using X-ray diffraction analysis in Lake Huahai, Hexi Corridor. The dolomite deposition was in deoxidizing environment during the Holocene according to the lithology, sediments characteristics, gypsum and the changes of $\mathrm{Fe}^{3+}$. It provided new evidence for the research of dolomite formation. Dolomite, as a kind of carbonate mineral, can indicate the lake water salinity. However, it can not indicate the salinity increase directly. The decrease of dolomite content is corresponded with the increase of salinity in sulfate lake. Dolomite and gypsum changes in Lake Huahai can be used to reconstruct lake salinity during the Holocene. During 10.47-8.87 cal ka B. P. , lake salinity was high, implying the climate change from arid to humid. During $8.87 \mathrm{cal} \mathrm{ka} \mathrm{B.} \mathrm{P.} \mathrm{,} \mathrm{a} \mathrm{mount} \mathrm{of} \mathrm{gypsum} \mathrm{deposition} \mathrm{revealed} \mathrm{increase} \mathrm{in} \mathrm{water} \mathrm{salinity} \mathrm{and}$ arid climate. After that, water salinity decreased and the climate was humid. After 5.50 cal ka B. P., hiatus indicated arid climate.
\end{abstract}

Keywords: Holocene; dolomite; gypsum; Lake Huahai; Hexi Corridor; lake evolution

白云石作为碳酸盐矿物的一种 ${ }^{[1]}$, 在地质历史中广泛分布, 在过去的研究中也被大量报道 ${ }^{[2-7]}$, 为白云 石的成因研究提供了丰富的证据. 以往的研究中, 在古近纪 ${ }^{[8-9]}$ 、新近纪 ${ }^{[10]}$ 等新生代地层中均发现白云石的 存在, 甚至在古生代、中生代等较老地层中也有报道 ${ }^{[9,11]}$. 而在全新世地层中虽然有所报道 ${ }^{[12-14]}$, 但其发现 的区域较上述时段远远偏小.

白云石成因和演化的问题目前仍有较大争论, 通过渗透回流 ${ }^{[1,15-18]}$ 、蒸发原、交代替换、微生物作用 ${ }^{[14]}$ 和次生交代 ${ }^{[5]}$ 等机制来解释白云石的成因, 为揭示白云石的形成和埋藏条件等问题提供了有益的参考. 上 述成因中, 对解释台地一盆地规模的白云石成因有相对系统的研究, 而对内陆干旱湖泊中白云石成因研究相

* 国家基础科学人才培养基金项目 ( J1210065, J1030519) 和兰州大学中央高校基本科研业务费专项资金项目 (lzujbky-2013-129, lzujbky-2013-127) 联合资助. 2012-10-29 收稿;2012-12-25 收修改稿. 李卓仑, 男, 1984 年 生,博士,讲师; E-mail: lizhuolunlzl@ 163. com. 
对稍显薄弱, 尤其是全新世以来白云石成因研究, 虽然通过内蒙古南部巴彦查干湖 ${ }^{[14]}$ 和青海湖 ${ }^{[19-20]}$ 的研究, 发现了全新世以来的白云石沉积,但与新生代其它时期形成的白云石在成因上有较大的差异. 因此,对内陆 干旱湖泊,尤其是对全新世以来白云石成因方面的研究仍需要进一步开展工作.

花海湖位于河西走廊的西段, 是一个典型的内陆干旱湖泊 ${ }^{[20-23]}$, 在以往的研究中受到了较多的关 注 ${ }^{[21-27]}$,构建了晚冰期以来的沉积序列 ${ }^{[28]}$, 并重建了特征时期的古环境特征 ${ }^{[25-27]}$. 在最近的研究中, 我们发 现在花海湖全新世的沉积物中, 有明显的白云石沉积. 探讨其白云石的形成环境, 不仅可以为白云石的形成 机制提供新的证据, 同时对深人理解该区域湖泊演化及古环境变化均有帮助. 基于此,本文以花海湖为研究 对象,研究全新世以来白云石形成的环境及其所揭示的环境意义.

\section{1 区域概况}

花海湖位于河西走廊西段玉门市东北约 $90 \mathrm{~km}$ 处, 现在的花海湖为一内陆干涸湖盆, 花海湖盆地海拔高 度约为 $1150 \sim 1250 \mathrm{~m}$, 为一南北宽达 $40 \mathrm{~km}$ 、东西长约 $70 \mathrm{~km}$ 的狭长低地, 在地质构造上属于花海-金塔盆地 的西部, 盆地南缘属中低山或中山区, 盆地内干燥多风, 每年 4-6 月为风季, 冬、春季多西北风, 有风天气不 小于 $300 \mathrm{~d}$. 夏季炎热, 气温可高达 $40^{\circ} \mathrm{C}$, 冬季最低温 $-26.7^{\circ} \mathrm{C}$, 年平均气温 $8^{\circ} \mathrm{C}$. 年平均降水量 $56 \mathrm{~mm}$, 多集 中在 6-8 月,年蒸发量达 $3000 \mathrm{~mm}$. 盆地内坡积洪积平原、洪积冲积平原、湖积平原等呈环带状分布,历史上 曾是疏勒河东支北石河、南石河和石油河及北大河支流断山口河的终端湖. 流域岩性除变质岩、火成岩外, 主要为碎屑岩、灰岩以及碎屑岩夹灰岩等. 盆地中部的湖积平原大多为红柳灌丛沙堆所占,地面起伏不平, 发育石膏灰棕漠土、草甸土、沼泽土等. 区内除花海乡(营盘堡)和花海农场等地附近有小片灌溉农田外,盆 地大部分为天然牧场,花海湖目前为一典型的干盐湖.

\section{2 研究方法}

研究剖面位于花海湖湖盆最低洼处 (图 1), 整个剖面 $17.25 \mathrm{~m}$, 其中 $9.25 \mathrm{~m}$ 至地表为新仙女木时期以来 的沉积 ${ }^{[27]}$. 整个剖面通过 13 个常规 ${ }^{14} \mathrm{C}$ 和 5 个 $\mathrm{AMS}^{14} \mathrm{C}$ 测年结果建立年代框架,剖面的描述和年表建立过程 及结果参见文献 $[28]$.

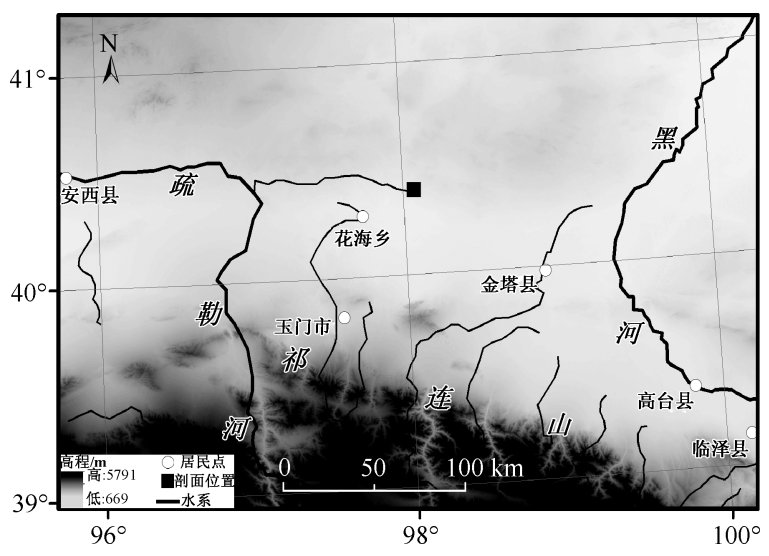

图 1 花海湖剖面位置

Fig. 1 The position of the profile in Lake Huahai

样品采集自下至上按 $5 \mathrm{~cm}$ 间隔系统采样, 自芒硝层中部淤泥细线 $(8.42 \mathrm{~m}$ ) 开始, 至 $40.5 \mathrm{~cm}$ 深度处结 束. 部分砂层采样间隔为 $10 \mathrm{~cm}$, 共采集样品 153 组. $\mathrm{Fe}^{3+}$ 测定在兰州大学西部环境教育部重点实验室进行, 实验前处理和测试方法见文献 [23].

样品的矿物种类及相对百分含量按照 $10 \mathrm{~cm}$ 间隔进行测量, 部分层位按照 $5 \mathrm{~cm}$ 间隔进行测量, 共计测 量样品 80 组. 样品经烘干研磨至 100 目左右后, 在兰州大学西部环境教育部重点实验室荷兰帕纳科公司的 
$X$-pert Pro 型粉晶 $X$ 射线衍射仪上完成测试.

矿物种类及相对百分含量的最终确定, 通过在该仪器自带的 X'Pert High Score Plus 软件分析后得出, 样 品中不同矿物的重量百分数计算公式为:

$$
X_{i}=\left(\frac{K_{i, n}}{I_{i, n}} \sum_{j=1}^{m} \frac{I_{j, n}}{K_{j, n}}\right)^{-1}
$$

式中, $X_{i}$ 为样品中 $i$ 矿物重量百分数; $K_{i, n}$ 和 $K_{j, n}$ 是矿物 $i$ 和 $j$ 分别在衍射线 $n$ 上的参照强度比值; $I_{i, n}$ 和 $I_{j, n}$ 是 矿物 $i$ 和 $j$ 分别在衍射线 $n$ 上的积分强度; $m$ 是样品中所有矿物的个数. 测定误差为 $\pm 5 \%$. 总外源碎屑岩矿 物重量百分数根据石英、白云母、钠长石和绿泥石重量百分数之和进行确定.

白云石和石膏的判定主要通过沉积物矿物组成的 XRD 图谱进行, 两者在衍射图中可以很好地与其他矿 物进行区分, 例如, 在深度 $210.5 \mathrm{~cm}$ 和 $80.5 \mathrm{~cm}$ 处衍射结果可以很好地判定白云石和石膏的存在 (图 2).
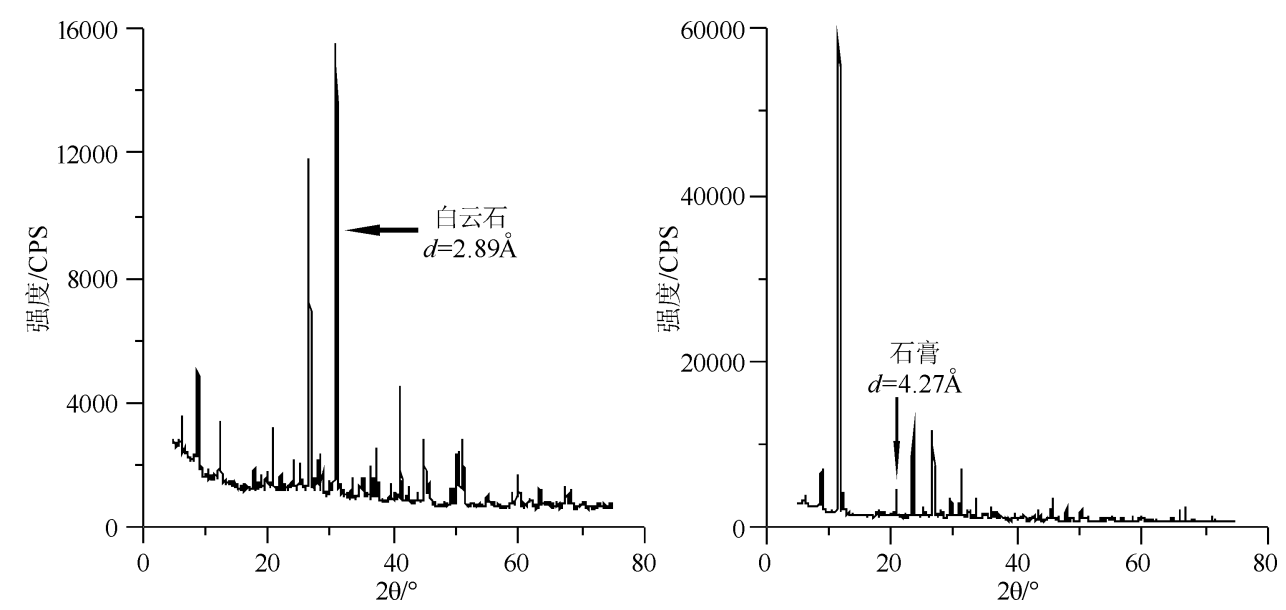

图 2 白云石 $(210.5 \mathrm{~cm}$ 深度沉积物) 和石膏 $(80.5 \mathrm{~cm}$ 深度沉积物 $) X$ 衍射图

Fig. 2 The X-ray diffraction diagram of dolomite ( sediment at the depth of $210.5 \mathrm{~cm}$ ) and gypsum( sediment at the depth of $80.5 \mathrm{~cm}$ )

\section{3 结果与分析}

$\mathrm{X}$ 衍射的结果显示, 整个剖面的沉积过程中, 白云石和石膏含量较为丰富, 自晚冰期以来白云石等矿物 含量随深度的变化见图 3. 由于本文的研究重点为全新世白云石的沉积环境, 全新世之前的白云石等矿物的 沉积环境将另文讨论.

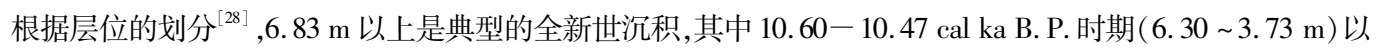
冲洪积和风成沉积为主 ${ }^{[21,28]}$, 白云石和石膏含量均较低, $\mathrm{Fe}^{3+}$ 含量相对较高, 显示了较强的氧化性特点. 而在 风成砂为主的风成沉积阶段 (5.25 4.53 m) , 白云石含量虽然有所上升, 但仍然低于 $10 \%$, 显示了在风成沉

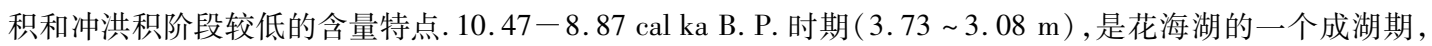
湖泊水位开始逐渐回升 ${ }^{[28]}$, 该时期白云石含量迅速降低, 石膏和 $\mathrm{Fe}^{3+}$ 含量突然增加. 8. 87-5.50 cal ka B. P. 时期 (3.08 0.73 m) , 白云石和石膏的含量均呈现明显的波动, 但二者呈现一定反相位关系. 白云石含量较 高的阶段, 均对应着石膏含量的低值. 与此同时, $3.08 \sim 2.30 \mathrm{~m}$ 深度中, $\mathrm{Fe}^{3+}$ 离子含量最低, 表明氧化性最 弱,湖泊水位升高 ${ }^{[21,27]} .5 .50-0 \mathrm{cal} \mathrm{ka} \mathrm{B.} \mathrm{P.} \mathrm{(} 0.73 \mathrm{~m}$ 至地表), 为现代的洪泛堆积.

\section{4 讨论}

\section{1 白云石的来源}

白云石是碳酸盐矿物 ${ }^{[1]}$, 湖泊沉积物中碳酸盐矿物的成因相对较为复杂, 既有可能是外源碎屑矿物, 又 


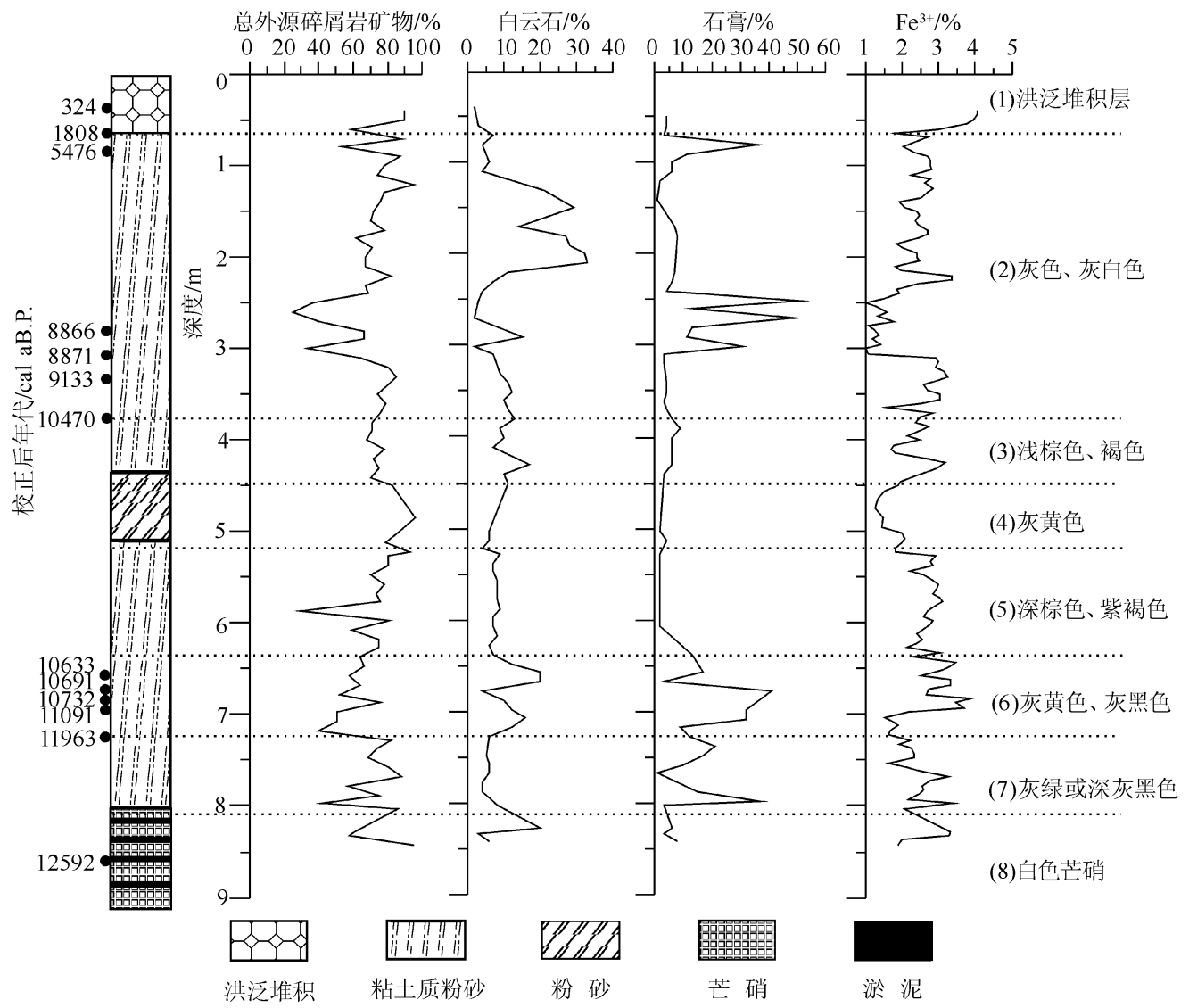

图 3 花海湖白云石和石膏含量变化

Fig. 3 Content changes of dolomite and gypsum in Lake Huahai

有可能是自生矿物. 但碎屑岩矿物往往为外源矿物 ${ }^{[29]}$, 通过碳酸盐矿物含量与外源碎屑岩矿物含量的相关 性高低再结合其他因素分析,进而判断碳酸盐矿物的自生与否,已经得到了应用 ${ }^{[29]}$.

将石英、白云母、钠长石和绿泥石四种典型的外源碎屑岩矿物的重量百分比之和与白云石重量百分比 进行相关分析, 通过对比不同沉积阶段的外源碎屑岩矿物与白云石的相关关系, 发现无论是冲洪积和风成 沉积为主的沉积阶段 (图 4a), 还是在湖相沉积为主的阶段 (图 4b), 白云石的含量变化与外源碎屑岩矿物的
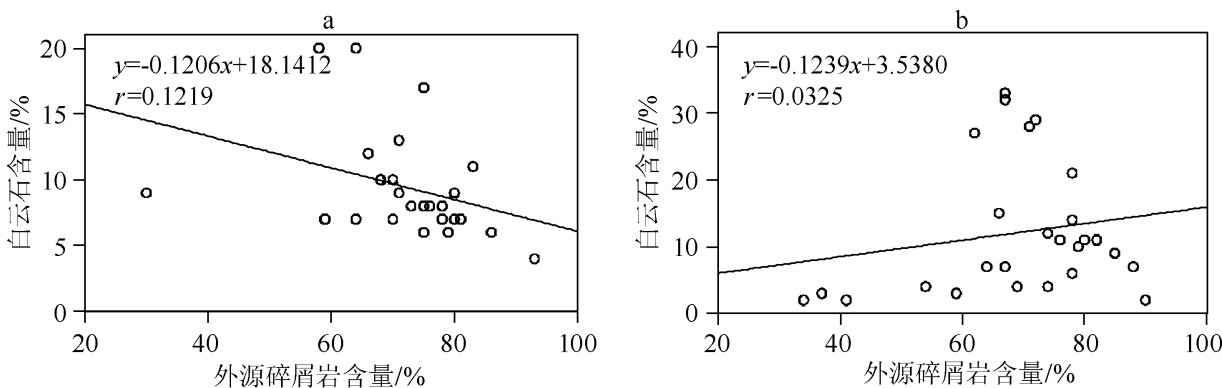

图 4 花海湖外源碎屑岩矿物与白云石的相关关系 ( a:6.30 3.73 m 深度, b:3.73 0.73 m 深度)

Fig. 4 Correlation between dolomite and clastic rocks from Lake Huahai ( $a$ : at the depth of $6.30-3.73 \mathrm{~m}, \mathrm{~b}$ : at the depth of $3.73-0.73 \mathrm{~m}$ ) 
含量变化相关性都很差. 若白云石矿物为外源的, 其含量变化应该同外源碎屑岩矿物含量的变化具有一定 的正相关关系, 反之亦然. 但从本文结果看, 二者没有明显的正相关关系. 同时, 流域的岩性主要是变质岩、 火成岩、碎屑岩、灰岩以及碎屑岩夹灰岩等, 没有白云石矿物的存在, 这亦是白云石是自生碳酸盐的重要证 据. 另外, 白云石作为外源碎屑矿物, 在淡水湖中较为常见, 而在咸水湖中发现较少 ${ }^{[30]}$, 而花海湖自晚冰期以 来, 即有明显的盐类矿物沉积, 包括芒硝、石膏等盐类矿物的沉积 ${ }^{[25-28]}$, 是典型的盐湖而非淡水湖, 综上, 花 海湖白云石应为自生的碳酸盐矿物.

\section{2 白云石沉积环境}

根据现代白云石的原生沉淀环境, 既有发现于像青海湖这样的微咸水湖 ${ }^{[18]}$, 又有发生在泻湖、浅海和盐 湖等盐度较高的水体 ${ }^{[31-32]}$. 以往的解释由于在盐度富集的过程中常伴随着强烈的水汽蒸发, 因此这些高盐 度水体的湖泊沉积物中白云石主要被解释为蒸发成因 ${ }^{[3,28]}$; 而在盐度较低的水体中, 则更倾向于微生物作用 的成因 ${ }^{[14,19]}$.

花海湖在晚冰期和新仙女木时期, 即以芒硝沉积为主 ${ }^{[25-28]}$, 在全新世时期, 又有典型的石膏沉积, 是一 个典型的盐湖. 王乃昂等 ${ }^{[28]}$ 通过对晚冰期以来花海古湖泊沉积特征分析研究指出, 8.87-5.50 cal ka B. P. (3.08 0.73 m) 存在深湖相沉积的气候湿润期, 为明显的还原环境. 在此阶段, 白云石和石膏的含量变化趋 势相反, 在白云石含量较高的阶段, 石膏含量却明显偏低. 由于石膏为暖相盐类矿物, 是干热气候的典型代 表, 指示干热、水体盐度高和蒸发作用强的气候条件 ${ }^{[30,33-34]}$. 因此, 两者相反的趋势变化, 指示了白云石在花 海湖泊沉积过程中并非直接受到蒸发作用的影响. 此外, 可以指示氧化环境强弱的 $\mathrm{Fe}^{3+}$ 含量变化在上述时 期与白云石含量在趋势上也呈现一定的相反趋势. 结合岩性表明, 该时期沉积环境以还原环境为主, 在还原 环境下, 白云石含量在整个剖面中含量最高, 同时, 受到氧化性强弱变化的影响, 在氧化性增强的时期, 白云 石含量相应地减少.

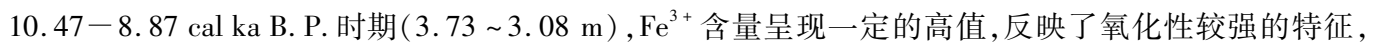
此时白云石含量开始降低, 揭示了氧化环境不利于白云石形成.

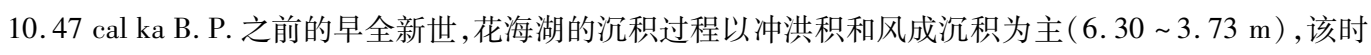
期湖泊水位较浅、接近干涸 ${ }^{[28]}$, 并伴有明显的风成砂沉积 ${ }^{[22]}$, 显示了明显的氧化环境. 同时, 该阶段岩性以 棕色、紫褐色黏土质粉砂为主 ${ }^{[28]}$, 是一种典型的氧化环境, 这种氧化环境无法在深湖相环境中进行, 是较干 旱的环境产物 ${ }^{[35]}$. 该阶段白云石含量较全新世中期明显偏少 (图 3), 同样显示了与还原环境相比, 在氧化环 境下白云石无法大量形成.

由此说明, 氧化环境并不利于白云石的形成; 相反, 还原条件有利于白云石的形成. 部分研究也发现, 在 现代的微咸水湖中报道的白云石均为典型还原环境下所形成的 ${ }^{[14,19]}$. 虽然目前在还原环境下形成白云石的 原因尚无定论, 但更倾向于在还原环境下有硫酸盐还原菌的参与 ${ }^{[36]}$. 虽然目前在形态上无法确定是否有还 原菌直接参与,但可以肯定的是, 在花海湖全新世沉积过程中, 还原环境利于白云石的形成.

\section{3 白云石沉积指示的环境意义}

白云石是碳酸盐矿物, 在全新世沉积环境中曾被认为是湖水咸化的直接证据, 进而成为指示干旱环境 的产物 ${ }^{[14]}$. 在干旱、封闭条件下, 湖泊经历从淡水、碳酸盐型、硫酸盐型, 进而演变成卤水盐湖的演化过 程 ${ }^{[37]}$, 即所谓的 “牛眼模式”. 郑绵平等 ${ }^{[38-39]}$ 将碳酸盐型再细分为强度、中度、弱度 3 种亚型. 由于在碳酸盐 型湖泊中, 湖水盐度逐渐升高, 初期的沉淀以方解石为主, 伴随着 $\mathrm{Ca}^{2+} 、 \mathrm{Mg}^{2+}$ 和 $\mathrm{CO}_{3}^{2-}$ 的沉淀, 湖水进一步咸 化, 在 $\mathrm{Ca}^{2+}$ 不断减少的过程中, 随着 $\mathrm{Mg} / \mathrm{Ca}$ 比值的增加, 直至形成高镁方解石、白云石和菱镁矿 ${ }^{[40]}$. 因此, 在 碳酸型盐湖的沉积过程中, 由方解石沉积过渡到白云石沉积, 可以认为是湖水咸化的一种标志.

但同时值得注意的是, 碳酸型只是干旱、封闭条件下湖泊演化过程中的一种, 其后仍经历硫酸型乃至卤 水盐湖的演化过程. 若在硫酸型湖泊沉积过程中, 譬如以石膏或芒硝沉积为主的阶段, 则白云石沉积无法作 为湖水咸化的重要标志; 相反, 应揭示湖水的相应淡化过程. 朱玉双等 ${ }^{[41]}$ 对三塘湖盆地中的白云石成因进行 研究时, 也认为白云石并非在高盐度环境下沉积, 而是淡水混人使湖水处于半咸水状态的产物. 本文的研究 也进一步表明, 在全新世时期, 石膏大量沉积时期并不利于白云石的形成 (图 3), 相反, 由于湖水的淡化, 硫 酸盐型湖泊中石膏含量减少, 白云石等碳酸盐才得以沉积. 因此, 在盐湖沉积过程中, 白云石沉积的出现虽 
然可以指示一定的盐度特征, 但并不一定是直接指示湖水的咸化, 需要进一步判定其他矿物沉积以及盐湖 类型,方能进一步揭示其环境意义.

花海湖在全新世期间白云石含量的变化, 可以间接地反映湖水盐度的变化过程. $\mathrm{X}$ 衍射结果显示了全新

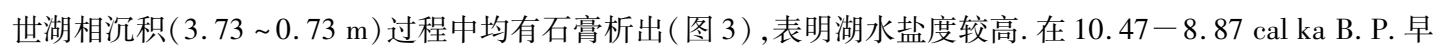
全新世时期 (3.73 3.08 m), 花海湖水位开始逐渐回升 ${ }^{[28]}$, 此时期白云石含量迅速降低, 石膏和 $\mathrm{Fe}^{3+}$ 含量 突然增加; 这主要是由于经历了早期的冲洪积和风成沉积为主的一种干旱环境 ${ }^{[28]}$, 此时虽然湖泊水位有所 回升, 但 $\mathrm{Fe}^{3+}$ 含量呈现一定的高值, 氧化环境相对较强 ${ }^{[28]}$, 湖泊水位较浅, 不利于白云石的形成, 石膏沉积 则反映了该时期湖水的盐度相对较高, 同时, 与前期洪泛堆积和风成砂的沉积相比,揭示了该时期气候由干

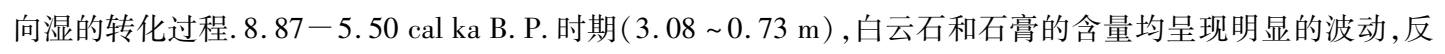
映此时湖水盐度的变化呈现一定的波动; 这主要是由于该阶段以还原环境为主 ${ }^{[28]}$, 利于白云石的形成,白云石 含量的增加与石膏含量相应地减少反映了该时期湖水盐度的波动变化. 由图 3 并结合野外观察发现, 3. 08 $2.53 \mathrm{~m}$ 是石膏含量最大的阶段, 有明显条带分布的菱板状石膏沉积 ${ }^{[28]}$, 同时 $3.08 \mathrm{~m}$ 处的 ${ }^{14} \mathrm{C}$ 年代结果表明

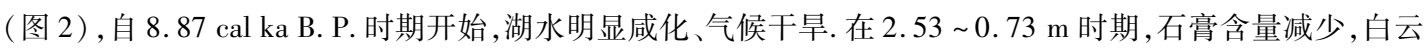
石含量增加, 表明该时期湖水较前期淡化. 同时该阶段呈现明显的深湖相沉积 ${ }^{228]}$, 表明该时期湖水盐度比

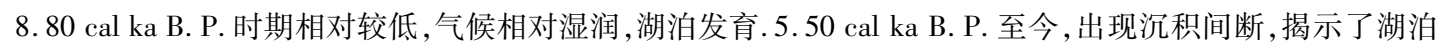
干涸、气候变干的特点.

\section{5 结论}

通过对花海湖沉积物的 $\mathrm{X}$ 衍射分析, 发现了全新世时期白云石的存在. 岩性、沉积过程、石膏以及 $\mathrm{Fe}^{3+}$ 含量的变化表明, 花海湖全新世白云石沉积的环境以还原环境为主, 还原环境利于白云石的形成.

白云石作为碳酸盐矿物, 可以反映一定的湖水盐度, 虽然其含量的变化可以指示湖水盐度的变化, 但并 非直接指示湖水的咸化. 随着湖水盐度的进一步增加, 在硫酸盐型湖泊中, 白云石含量随盐度的增加而相应 地减少.

结合石膏含量的变化, 花海湖全新世时期白云石含量的变化可以揭示该区域湖水盐度的变化. 在 10.47-

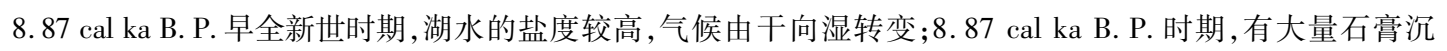

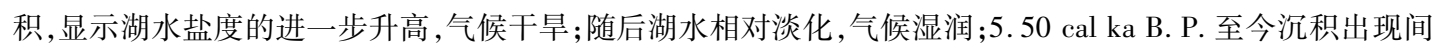
断, 气候逐渐干旱.

致谢: 感谢审稿人对本文提出的宝贵修改意见.

\section{6 参考文献}

[ 1 ] 冯增昭. 关于白云岩、白云石、白云岩化、白云石化和白云化等术语的辨析. 古地理学报, 2012,14(2):218.

[ 2 ] 冯增昭. 沉积岩岩石学 (上册)——碳酸盐岩概论. 北京: 石油工业出版社, 1982:177-221.

[3] Warren J. Dolomite: Occurrence, evolution and economically important associations. Earth Science Reviews, 2000, 52 : $1-81$.

[ 4 ] 汤朝阳,王敏,姚华舟等. 白云岩化作用及白云岩问题研究述评. 东华理工学院学报,2006,29(3):205-210.

[ 5 ] 张学丰, 胡文瑄, 张军涛. 白云岩成因相关问题及其主要形成模式. 地质科技情报, 2006,25(5): 32-40.

[ 6 ] 张学丰,刘 波,蔡忠贤等. 白云岩化作用与碳酸盐岩储层物性. 地质科技情报,2010,29(3): 79-85.

[ 7 ] 李 波,颜佳新,刘喜停等. 白云岩有机成因模式: 机制、进展与意义. 古地理学报, 2010,12(6):699-710.

[ 8 ] Lucia FJ, Major RP. Porosity evolution through hypersaline reflux dolomitization. In: Purser BH, Tucker ME, Zenger DH eds. A Volume in honor of dolomieu. International association of sedimentologists. Cambridge: Blackwell Scientific Publications, 1994: 325-341.

[ 9 ] Fouke BW, Beets CJ, Meyers WJ et al. ${ }^{87} \mathrm{Sr} /{ }^{86} \mathrm{Sr}$ chronostratigraphy and dolomitization history of the Seroe Domi, Curacao (Netherlands Antilles). Facies, 1996, 35: 293-320.

[10] 廖 静, 董兆雄, 翟桂云等. 渤海湾盆地歧口凹陷沙河街组一段下亚段湖相白云岩及其与海相白云岩的差异. 海相 油气地质, $2008, \mathbf{1 3}(1): 18-24$. 
[11］王小芬,杨 欣. 鄂尔多斯盆地富县地区马五段碳酸盐岩成岩作用研究. 岩性油气藏,2011,23(3):75-79.

[12] Adams JF, Rhodes ML. Dolomitization by seepage refluxion. American Association of Petroleum Geologists Bulletin, 1960, 44(12): 1912-1920.

[13] Rivadeneyra MA, Parraga J, Delgado R. Biomineralization of carbonates by Halobacillus trueperi in solid and liquid media with different salinities. FEMS Microbiology Ecology, 2004, 48(1) : 39-46.

[14] 姜文英, 吴海斌, 储国强等. 内蒙古巴彦查干湖白云石的成因及其环境意义. 第四纪研究, 2010,30(6):1116-1120.

[15］冯增昭. 石油地质学译文集——碳酸盐岩沉积环境. 北京: 科学出版社,1980:1-152.

[16] 陈永权,周新源,杨文静. 白云石形成过程中的热力学与动力学基础及白云岩形成环境. 海相油气地质,2009,14 (1) $: 20-25$.

[17] Fanning KA, Byrne RH, Breland II JA. Geothermal springs of the West Florida Continental shelf-evidence for dolomitization and radionuclide enrichment. Earth and Planetary Science Letters, 1981, 52 : 345-354.

[18] Warren J. Evaporites: Their evolution and economics. Oxford: Blackwell Science, 1999: 1-438.

[19] 于炳松, 董海良, 蒋宏忱等. 青海湖底沉积物中球状白云石集合体的发现及其地质意义. 现代地质,2007,21 (1): 66-70.

[20] 邓诗财. 青海湖底沉积物中白云石的微生物成因机理研究 [ 学位论文]. 武汉: 中国地质大学, 2010:66-70.

[21] 王乃昂,王 涛,高顺尉等. 河西走廊末次冰期芒硝和砂楔与古气候重建. 地学前缘, 2000,7 (增刊):59-66.

[22] 胡 刚,王乃昂,罗建育等. 花海湖泊古风成砂的粒度特征及其环境意义. 沉积学报,2001,19(4):642-647.

[23] 胡 刚. 花海晚第四纪古湖泊记录研究 [学位论文].兰州:兰州大学,2002.

[24] 胡 刚,王乃昂,赵 强等. 花海湖泊特征时期的水量平衡. 冰川冻土,2003,25(5):485-490.

[25] Wang NA, Zhang JM, Cheng HY et al. The age of formation of the mirabilite and sand wedges in the Hexi Corridor and their paleoclimatic interpretation. Chinese Science Bulletin, 2003, 48(14) : 1439-1445.

[26] Wang NA, Zhao Q, Li JJ et al. The sand wedges of the Last Ice Age in the Hexi Corridor, China: Paleoclimatic interpretation. Geomorphology, 2003, 51(4) : 313-320.

[27] Wang NA, Li ZL , Li Y et al. Younger Dryas event recorded by the mirabilite deposition in Lake Huahai, Hexi Corridor, NW China. Quaternary International, 2012, 250 : 93-99.

[28] 王乃昂, 李卓仑, 李 育等. 河西走廊花海剖面晚冰期以来年代学及沉积特征研究. 沉积学报, 2011, 29(3): $552-560$.

[29] 姚 波, 刘兴起, 王永波等. 可可西里库赛湖 KS-2006 孔矿物组成揭示的青藏高原北部晚全新世气候变迁. 湖泊科 学, 2011,23(6) : 903-909.

[30］田 馨,向 芳,罗 来等. 陆相特殊沉积的研究方法及气候意义. 地学前缘,2009,16(5): 71-78.

[31] Hsu KJ, Siegenthaler C. Preliminary experiments on hydrodynamic movement induced by evaporation and their bearing on the dolomite problem. Sedimentology, 1969, 1(2): 11-25.

[32] Warren JK. Sedimetology of Coorong dolomite in the Salt Creek region, South Australia. Carbonates and Evaporites, 1988, 3: 175-199.

[33 ] Jin ZD, Wu YH, Zhang XH et al. Role of late glacial to mid-Holocene climate in the catchment weathering in the central Tibetan Plateau. Quaternary Research, 2005, 63(2) : 161-170.

[34] 郑绵平,赵元艺, 刘俊英. 第四纪盐湖沉积与古气候. 第四纪研究, 1998, (4) : 297-307.

[35] Berner RA. A new geochemical classification of sedimentary environments. Journal of Sedimentary Research, 1981, 5: 359-365.

[36] Bosak T, Souza-Egipsy V, Corsetti FA et al. Micrometer-scale porosity as a biosignature in carbonate crusts. Geology, $2004, \mathbf{3 2}(9)$ : $781-784$.

[37] Valyashk MG. Basic chemical types of natural waters and the conditions producing them. Records of the Academy, USSR, 1950,102 : 315-318.

[38] 郑绵平,刘文高,向 军等. 论西藏盐湖. 地质学报, 1983,57(2):185-194.

[39] 郑绵平, 向 军,魏新俊等. 青藏高原盐湖. 北京: 科学技术出版社, 1989:1-431.

[40] 郭 峰. 碳酸盐岩沉积学. 北京: 石油工业出版社,2011:224-234.

[41] 朱玉双,柳益群,周鼎武. 三塘湖盆地中二叠统芦草沟组白云岩成因. 西北地质, 2009,42(2):95-99. 